\title{
Specific features of drilling mode with extendable working elements
}

\author{
Boranbay Ratov ${ }^{1,4}$, Boris Fedorov ${ }^{1}$, Andrii Sudakov ${ }^{2 *}$, Indira Taibergenova ${ }^{1}$, and Saltanat \\ Kozbakarova $^{3}$ \\ ${ }^{1}$ Satpayev University, Institute of Geology, Oil and Mining named after K. Turysova, 22 Satpayev St. \\ 050013, Almaty, Kazakhstan \\ ${ }^{2}$ Dnipro University of Technology, Department of Oil and Gas Engineering and Drilling, \\ 19 Yavornytskoho Ave., 49005, Dnipro, Ukraine \\ ${ }^{3}$ Yessenov University, Department of Oil and Gas Engineering and Geology, 32 Microdistrict, \\ 130000, Aktau, Kazakhstan \\ ${ }^{4}$ Caspian University, Department of Geology and Oil Gas, 521 Seyfulin Ave., 050000, Almaty, \\ Kazakhstan
}

\begin{abstract}
The work is devoted to the calculation of the main technological parameters of a bit of a new patented design, the essence of which is to replace worn out working elements (carbide cutters or diamond-containing matrices) during drilling with a new, not blunt tool right at the bottom of the well. The need to correct the calculation method is associated with the design feature of the new crown, which consists in the fact that when using it, an annular bottom of a larger width is formed compared to serial crowns of the same outer diameter. Therefore, the known formulas for carbide and diamond drilling have been supplemented with appropriate correction values so that the ROPs when using new and serial bits are the same during full development. So, when using carbide cutters as rock-cutting elements, a correction factor is introduced that increases the number of main cutters in the crown sectors of the first and second stages. In diamond cutting, it is necessary to increase the maximum speed of the tool, taking into account the mining technical conditions of penetration. Refined formulas for calculating the parameters of the drilling mode allow preserving the advantages of bits with extendable working elements and increasing the drilling speed by 1.7-1.8 times compared to existing serial bits.
\end{abstract}

\section{Introduction}

The current trend in the development of coal, oil and gas production in Ukraine indicates the necessity of applying new approaches to the formation of a raw material base, such as allocation of alternative sources of hydrocarbon raw materials in a separate industrial branch. Being the most environmentally friendly utility product, natural gas will continue to play an important role in the energy supply and future development of the world's energy [1-3]. The fuel and energy complex in the developed countries of the world is a complex system of

*Corresponding author: sudakovy@ukr.net 
material production that contains a set of many subsystems covered the production, processing, distribution, storage and consumption of energy carriers [4, 5].

The Black Sea contains large reserves of hydrocarbons. Obviously, gas hydrates are potentially promising energy source. The geopolitical situation in the world can will changed because mining of gas hydrates deposits in the Black Sea (World Ocean). Many countries have already launched extensive research on gas hydrates.

Despite the evidences of hydra deposits in the Black Sea, Ukraine is lagging far behind in the work on this problem. The primary aim is to delineate gas hydrate deposits and estimation of real hydrates volumes using geophysical, primarily seismoacoustic methods, and further drilling.

Involving new fields and increase hydrocarbon production is possible only for a network of well drilling.

Drilling of exploration and exploration wells, both onshore and offshore, is carried out with coring. In this case, the destruction of the rock occurs with an annular tool - crowns. Depending on the mechanical properties of the rocks, carbide or diamond tools are used. For soft and medium-strength rocks, hard-carbide crowns are used.

In recent years, carbide drilling in combination with diamond drilling has been widely used. According to the data, the rocks from the first to the seventh drillability categories make up $77.6 \%$ of the total drilling volume. These rocks are drilled mainly with carbide bits. The latter can be used successfully in drilling quartz-free rocks of the eighth-ninth categories such as pyroxenites, gabbros, basalts and others.

All carbide core bits are multi-bit.

The process of destruction of rocks is one of the most energy-intensive technological operations. Especially when drilling deep wells, when the rock mass surrounding the well is in a stressed state under the influence of high rock pressure $[6,7]$. Therefore, the search for ways to weaken the rock during drilling is an important practical task $[8,9]$.

Many works of domestic and foreign scientists are devoted to the study of the processes of destruction of rocks. The main approach used by researchers of the process of destruction of rocks during drilling earlier and are currently using in view of the specifics of the process of destruction itself is the study of the macroscopic laws of the process [10, 11].

In works [12] it is noted that the mode of rock destruction and its inherent basic regularities have much in common during the operation of a drilling rig for exploration core drilling, a rotary drill for drilling wells for oil, an electric drill for drilling boreholes and cutting machines.

The beginning of the scientific study of cutting processes in the 60-70s of the XIX century was laid by I.A. Tima, the cutting scheme of which was developed by K.A. Zvorykin, A.A. Briks, V.A. Guskov.

The modern cutting theory can be presented as follows. Under the action of axial force, the cutter penetrates into the bottomhole rock to a certain depth, crushing and crushing it with its edges. Under the action of the rotational force, the cutter embedded in the rock compresses it with its front edge. The rock is crushed, crushed and squeezed up along the front edge of the cutter. As a result of compressive stresses, tensile stresses that are perpendicular to the direction of movement of the cutter arise, which lead to the separation of rock elements. After the separation of the rock element, the cutter, experiencing a reduced reaction from the side of the face, continues its movement, cleaning up the unevenness of the bottom. Having passed the space freed from the rock, the cutter again meets the frontal resistance of the rock ledge, and the cycle of destruction is repeated.

The separation of the rock element occurs along the lower surface and lateral, one or two, depending on the arrangement of the incisors in the crown. In this case, in addition to axial and rotational forces, friction forces act on the cutter along the end face of the cutter, along the side, front and rear edges, which cause wear of the cutter. 
The result of the interaction of the cutter with the rock are the values of penetration of the cutter into the bottomhole rock and the circumferential force on the cutter, which determine the drilling speed and the amount of torque on the bit.

\section{Analysis of recent research and publications}

Nowadays the industry for core drilling produces carbide bits, type $\mathrm{M}$ bits are produced for drilling soft, loose, unstable rocks of low abrasiveness, the first - fourth in drillability. And also, nine types of bits CM, CA, ST for drilling mediumhard rocks. Each type of drill bit has its own area of application in terms of abrasiveness, fracturing of rocks and their categories of drillability $[13,14]$.

Various areas of application of crowns have left their mark on their design features.

Analysis of the designs of carbide bits shows that:

- in most crowns, the incisors are set in steps, which provides additional exposed surfaces;

- oriented insertion of cutters in two directions - radial and axial is widely used, which ensures the presence of twosided front negative angles, inclination of the cutting edges to the radius and bottom, contact with the borehole wall and core along the line, and not the face;

- to increase the resistance of the crown diameter, they are equipped with additional external scoring cutters installed in the flushing grooves and not participating in the operation of the crown along the butt-end, however, despite this measure, in a number of cases there is still significant stagnation of wells;

- the shape of the cross section of the incisors at the base is isometric - square, octahedron, rectangular in two crowns;

- the width of the incisors is less than the width of the cutting ring, which leads to a multirow design of the crowns - from two to five rows of incisors, except for the CA1 crown;

- although the location of the cutting edges of the incisors is intermittent, all types of crowns provide for complete overlapping of the bottom with incisors, with the exception of the CA3 crown;

- all crowns are small - or micro-incisor, multi-incisor crowns $[15,16]$.

The serially produced solid carbide bits of the CM, CA, and CT types have made it possible to increase the productivity of drilling operations, however, there are possibilities for further increasing the productivity of drilling with a carbide rock cutting tool.

Given the state of the issue under consideration, the following main areas of work to further increase work productivity can be distinguished [17, 18]:

- theoretical and experimental study of the processes of destruction of rocks with a cutting tool;

- improvement of crown design;

- improving the technology for manufacturing crowns;

- improving the technology of operating crowns.

In connection with the above, the purpose of the research is to create an effective rock cutting tool for core drilling of exploration wells and to establish some regularities in the process of rock destruction during drilling.

\section{Results and discussion}

By the authors, in order to increase the running speed of drilling, a bit with retractable working rock-breaking elements has been developed [19].

Fig. 1a shows a general view of the crown (a fragment of the assembly drawing) and its made full-scale sample (Fig. 1b). 

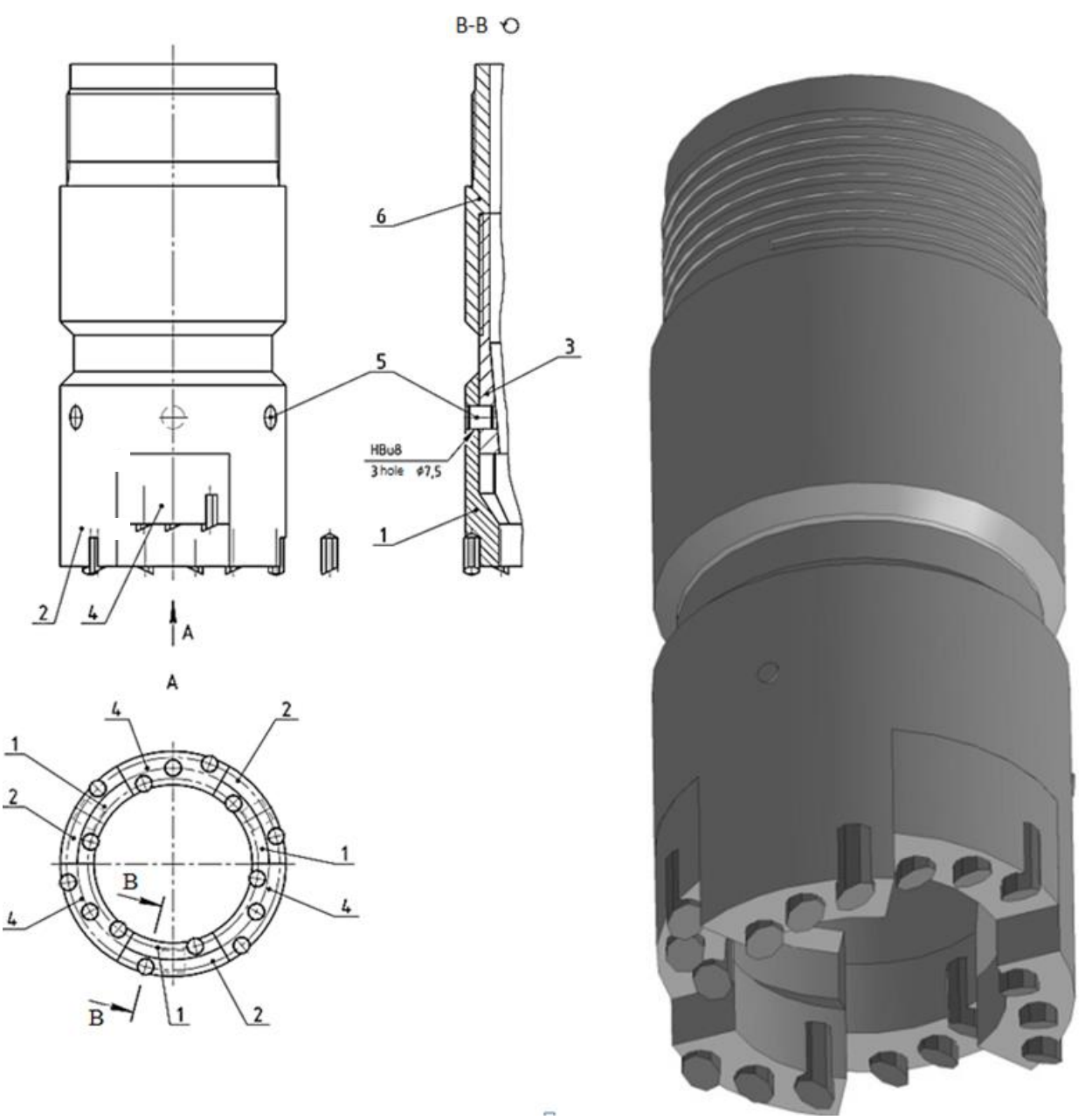

Fig. 1. Drill bit with retractable working elements: A - A fragment of an assembly drawing; B - a full-scale sample; 1 - inner body with incisors; 2 - outer body with cutters; 3 - adapter; 4 - sector with cutters of the inner body; 5 - clamps; 6 - carbide cutters.

The bit contains an outer body 1 with three sectors 2 with incisors placed through $120^{\circ}$, and an inner body 3 with three sectors 4 , the latter entering the grooves of the outer body and initially located above the bottom of the well at a certain distance. Both bodies are secured against movement by clamps 5 . The bit through the adapter 6 is connected to the drill string (not shown in the figure) which is rotated by the drilling rig.

Initially, during drilling, the annular bottom is deepened by the cutters of sectors 2 . Then, after they have worked out (bluntness and wear), an additional load is transferred through the drill string, sufficient to cut the retainers 5 . As a result, the inner body 3 goes down and the cutters of sectors 4 are installed at the bottom. With the supply of a rational axial load, rotational speed and flow rate of the drilling mud, the deepening of the bottom continues. Only when the cutters mentioned are worn out does the entire drill string rise to the surface.

The advantage of such a bit over the known designs is to increase the residence time of the tool at the bottom, i.e. in increasing the running speed of drilling and, therefore, in increasing the overall productivity of drilling operations. 
The drill bit with working pull-out elements in the form of the latter can be made in two modifications:

- the working element is made in the form of carbide or diamond-carbide PDC cutters, fixed in the steel sectors of the body 1.3 bits;

- working elements represent diamond-bearing matrices fixed on the sectors of the bit bodies.

The bit made according to the first option is recommended for drilling in soft and medium-hard non-abrasive formations. The second bit should be used in medium-hard and hard rocks, including abrasive rocks. Consider the features of the technology of drilling with a bit made in the above options.

1. Drilling with a new bit equipped with carbide cutters. Mechanical speed of drilling with such a bit is determined by the formula [20-22]:

$$
\vartheta_{\text {tech }}=\frac{\eta C_{0} m n}{(R-z) \operatorname{tg} \alpha H_{b}},
$$

where $\eta$-coefficient depending on the angle of internal friction of the rock and the angle of sharpness of the cutter; $C_{0}$ - axial load on one main cutter, $H$; $m$ - number of main incisors; $n$ - crown rotation frequency, $\mathrm{rpm} ; R, r$ - respectively, the outer and inner radii of the crown, $\mathrm{m} ; \alpha$ - cutter angle; $H_{b}$ - drill rock hardness, MPa.

Due to the design features of a crown with retractable elements, the width of the annular face will be greater than that of a standard crown of the same outer diameter.

Let us denote in (1) all parameters, except for the quantity $\frac{1}{R-r}$, through $B_{1}$ we have:

$$
\vartheta_{\text {tech }}=\frac{B}{R-r}
$$

From (2) it can be seen that if all the quantities denoted by $B$ do not change, then the ROP is inversely proportional to the width of the annular bottom. From the design features of the crown with retractable elements, it follows that the width of the annular face formed during its use will be greater than that of standard crowns while maintaining the same standard diameter of both tools. If we denote the outer radii of the tools $R$, and the inner ones through $\mathrm{r}$ (bits with extendable elements) and $\mathrm{r}_{0}$ (standard bit), then the ratio of the ROP will be:

$$
\frac{\vartheta_{\text {tech }}}{\vartheta_{\text {tech }_{0}}}=\frac{R-r_{0}}{R-r}
$$

where $\vartheta_{\text {tech }}, \vartheta_{t e c h_{0}}$ are respectively, the drilling speed of the bit with pull-out elements and the standard bit.

Let us explain the relation (3) with an example [23]: the outer diameters of both crowns $R=76 / 2=38 \mathrm{~mm}$; inner radii: $r_{0}=59 / 2=29.5 \mathrm{~mm} ; r=48 / 2=24 \mathrm{~mm}$. Substituting the data in (3), we get:

$$
\frac{\vartheta_{\text {tech }}}{\vartheta_{\text {tech } 0}}=\frac{38-29.5}{38-24}=\frac{8.5}{14}=0.61
$$

those, the drilling speed of the bit with a sliding element will be $\vartheta_{\text {tech }}=0.61 \vartheta_{\text {tech } 0}$, i.e. will decrease by $40 \%$. To maintain a constant drilling speed, you need to enter the coefficient $K=14 / 8.5=1.65$, which increases the value of either the axial load, or the rotational speed of the bit or the number of main cutters. An increase in axial load and rotational speed, the 
rational values of which are included in formula (1), is inappropriate, since this leads to rapid abrasive wear of working elements. The most acceptable is to increase the number of main incisors to $m_{p}=1.65 \mathrm{~m}$. For example, if in a standard CM-76 crown the number of main incisors is $m=12$, then in a crown with retractable elements there should be $m_{p}=1.65 \cdot 12 \approx$ 20 pieces. Since these incisors need to be divided into three sectors, 6 incisors will be placed in each of them, i.e. only 18 incisors. For the full use of the multiplying factor (residual coefficient $K_{r m f}=0.15$ ), it is recommended to increase the axial load additionally by a small amount.

Thus, the mechanical speed of drilling with a crown with pull-out elements, taking into account the increasing coefficient, is determined by the formula:

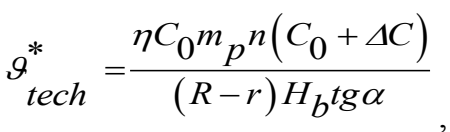

where $\Delta C$ - the largest increment in the axial load, which compensates for the residual multiplying factor (in this case, $K_{r m f}=0.15$ ).

The recommended rational axial load on one main cutter $C_{0}$ and the rotational speed are known for each type of crown and are given in the literature [24, 25].

The third technological parameter - the drilling fluid flow rate is not included in the formula (4), however, it requires adjustment due to the large amount of cuttings caused by the increase in the width of the annular bottom when drilling with a crown with retractable cutters. Calculations show that the volume of cuttings generated is about 1.5 times greater when drilling with a new bit compared to a standard bit.

In practice, the flow rate $Q$ of the drilling fluid is calculated using a simple formula [23, 24]:

$$
Q=q d_{b}
$$

where $q$ - specific consumption of flushing fluid per $1 \mathrm{~mm}$ of bit diameter, $\mathrm{m}^{3} / \mathrm{sec} * \mathrm{~mm}, q$ is value depends on the category of drillability, hardness and abrasiveness of rocks and varies from $13 \cdot 10^{-5}$ up to $2.0 \cdot 10^{-5} \mathrm{~m}^{3} / \mathrm{sec} \cdot \mathrm{mm}$ [26]; $d_{b}$ - borehole diameter (taken equal to the outer diameter of the bit).

However, since when drilling with a new bit, the amount of cuttings formed is much greater, in the formula (5) it is necessary to enter the increasing coefficient $K_{i c}$ :

$$
Q=K_{i c} q d_{b}
$$

where $K_{i c}=\mathrm{S}_{\text {new }} / S_{\text {ser }},\left(S_{\text {new }}, S_{\text {ser }}\right)$ are respectively, the area of the annular face when using new and serial bits).

2. Drilling with a new retractable bit, the working elements of which are a diamondbearing matrix.

The drilling speed with a diamond bit can be determined by the formula [27]:

$$
\vartheta_{m}=\frac{0.4 n P f_{0}}{d_{b} \sigma_{c s}\left(1-\frac{d_{w}}{d_{b}}\right)},
$$

where $n$ - bit rotation frequency, rpm; $P$ - the axial load on the crown, daN; $f_{0}$ - coefficient of friction of the bit end on the bottom hole; $d_{w}, d_{b}$-respectively the well and core diameters, cm; $\sigma_{c s}$ is ultimate compressive strength of drilled rock, daN $/ \mathrm{cm}^{2}$.

In turn, the total axial load $P$ on the bit is determined from the following dependence [27]: 


$$
P=P_{S} \cdot F \text {, }
$$

where $P_{s}$-specific load, daN $/ \mathrm{cm}^{2}$; depending on the category of rock drillability and varying from $60 \mathrm{daN} / \mathrm{cm}^{2}$ in rocks of category VII to $150 \mathrm{daN} / \mathrm{cm}^{2}$ in rocks of XII category; $F$ - working area of the crown end (excluding the flushing channels).

The end areas of the serial $F_{\text {ser }}$ and new $F_{\text {new }}$ crowns with the same outer diameter are equal:

$$
F_{\text {ser }}=\pi / 4\left(D_{n}^{2}-d_{i n}^{2}\right)-t b ; F_{n e w}=\pi / 4\left(D_{n}^{2}-d_{i n_{0}}^{2}\right): 3
$$

where $D_{n}$-the outer diameter; $d_{i n}$-internal diameter of the serial crown; $d_{i n 0}-$ inner diameter of the new crown; $t, b, c$-respectively the width, radial size and number of flushing channels in the serial crown.

As an example, we will calculate the mentioned areas for the initial data of the dimensions mentioned earlier: $D_{n}=76 \mathrm{~mm} ; d_{\text {in }}=59 \mathrm{~mm} ; d_{\text {in } 0}=48 \mathrm{~mm} ; t=5 \mathrm{~mm} ; b=(76-$ $59) / 2 \approx 8 \mathrm{~mm} ; c=6$. Then: $F_{\text {ser }}=0.785\left(76^{2}-59^{2}\right)-5 \cdot 86=1562 \mathrm{~mm}^{2} . F_{\text {new }}=0.785\left(76^{2}-\right.$ $\left.48^{2}\right): 3=908 \mathrm{~mm}^{2}$. From a comparison of $F_{\text {ser }}, F_{\text {new }}$ it follows that the area of the end face of a serial crown is $1546 \mathrm{~mm}^{2} / 908 \mathrm{~mm}^{2}=1.7$ times more than the area of the end face of a new crown. Therefore, the axial load on the latter should be correspondingly less. Let's say for rocks of IX category $P_{y}=75 \mathrm{daN} / \mathrm{cm}^{2}$. Then the total load on the serial bit will be $P_{\text {ser }}=$ $75 \cdot 15.62 \approx 1170 \mathrm{daN}$, and on the new bit: $P_{\text {new }}=75.9 .08 \approx 680 \mathrm{daN}$, which, naturally, in accordance with formula (7), reduces the mechanical speed of drilling.

In diamond drilling, the rotational speed is assumed to be significantly higher than in hard-alloy, and is assigned in the range of 800-1700 rpm and is limited by fracturing and displacement of rocks, the depth and diameter of the well, as well as the power of the drilling rig.

In all cases, to compensate for the decrease in the drilling speed caused by the reduced area of the bit face, the bit rotation frequency that is maximum possible under the given mining technological drilling conditions should be assigned.

The drilling mud flow rate is calculated by the formula (6). At the same time, the value of q varies depending on the category of rock drillability and is assigned in the range from $0.5 \cdot 10^{-5} \mathrm{~m}^{3} / \mathrm{s} \cdot \mathrm{mm}$ up to $2 \cdot 10^{-5} \mathrm{~m}^{3} / \mathrm{s} \cdot \mathrm{mm}$.

\section{Conclusions}

1. The proposed drill bit with retractable working elements, when properly used, can significantly increase the running speed of drilling.

2. When equipping a new drill bit with carbide cutting tools, in order to maintain the mechanical speed of drilling, the number of main cutters should be increased in accordance with the obtained formula (4).

3. When equipping a new drill bit with diamond-containing equipment, in order to maintain the mechanical speed at a high level, the tool rotation frequency should be increased as much as possible, as far as the mining technical conditions of drilling allow.

4. Due to the fact that the use of a new bit causes the formation of a wider annular bottom of the wells, it is necessary to increase the fluid flow rate in order to clean the well from gland formation in accordance with the obtained relationship [28].

The study was financed/funded/financed by the Science Committee of the Ministry of Education and Science of the Republic of Kazakhstan (grant 2018/No. AP05130856) and within the framework of the project "Determination of the regularities of phase transformations and stresses of gas hydrates. Deformed state of the rock mass and the development of innovative geotechnologies" (No. of state registration 0119U000249). 


\section{References}

1. Bondarenko, V., Kovalevs'ka, I., \& Ganushevych, K. (2014). Progressive technologies of coal, coalbed methane, and ores mining. London, United Kingdom: CRC Press, Taylor \& Francis Group. https://doi.org/10.1201/b17547

2. Bondarenko, V.I., \& Sai, K.S. (2018). Process pattern of heterogeneous gas hydrate deposits dissociation. Naukovyi Visnyk Natsionalnoho Hirnychoho Universytetu. (2), 21-28. https://doi.org/10.29202/nvngu/2018-2/4

3. Bondarenko V., Kovalevska I., Astafiev D., \& Malova O. (2018). Examination of phase transition of mine methane to gas hydrates and their sudden failure - Percy Bridgman's effect. Solid State Phenomena, (277), 137-146. https://doi.org/10.4028/www.scientific.net/SSP.277.137

4. Lozynskyi, V., Medianyk, V., Saik, P., Rysbekov, K., \& Demydov, M. (2020). Multivariance solutions for designing new levels of coal mines. Rudarsko Geolosko Naftni Zbornik, 35(2), 2332. https://doi.org/10.17794/rgn.2020.2.3

5. Khomenko, O., Kononenko, M., \& Myronova, I. (2018). Increasing ecological safety during underground mining of iron-ore deposits deposits. Naukovyi Visnyk Natsionalnoho Hirnychoho Universytetu, (2), 29-38. https://doi.org/10.29202/nvngu/2018-2/3

6. Sai, K., Malanchuk, Z., Petlovanyi, M., Saik, P., \& Lozynskyi, V. (2019). Research of Thermodynamic Conditions for Gas Hydrates Formation from Methane in the Coal Mines. Solid State Phenomena, (291), 155-172. https://doi.org/10.4028/www.scientific.net/SSP.291.155

7. Khomenko O.Ye., Sudakov, A.K., Malanchuk, Z.R., \& Malanchuk, Ye.Z. (2017). Principles of rock pressure energy usage during underground mining of deposits. Naukovyi Visnyk Natsionalnoho Hirnychoho Universytetu, 2(158), 34-43.

8. Bondarenko, V., Svietkina, O., \& Sai, K. (2018). Effect of mechanoactivated chemical additives on the process of gas hydrate formation. Eastern-European Journal of Enterprise Technologies, 6(91), 17-26. https://doi.org/10.15587/1729-4061.2018.123885

9. Ovchynnikov, M., Ganushevych, K., \& Sai, K. (2013). Methodology of gas hydrates formation from gaseous mixtures of various compositions. Annual Scientific-Technical Collection - Mining of Mineral Deposits, 203-205. https://doi.org/10.1201/b16354-37

10. Kovalevska, I., Zhuravkov, M., Chervatiuk, V., Husiev, O., \& Snihur, V. (2019). Generalization of trends in the influence of geomechanics factors on the choice of operation modes for the fastening system in the preparatory mine workings. Mining of Mineral Deposits 13(3), 1-11. https://doi.org/10.33271/mining13.03.001

11. Lozynskyi, V.H., Dychkovskyi, R.O., Falshtynskyi, V.S., \& Saik, P.B. (2015). Revisiting possibility to cross disjunctive geological faults by underground gasifier. Naukovyi Visnyk Natsionalnoho Hirnychoho Universytetu, (4), 22-28.

12. Roy, N., Solovyov, V., Dmytrenko, V., \& Savyk, V. (2019). On modern possibilities of research on gas and gas-condensate wells in any filtering mode. International Journal of Engineering \& Technology, 7(4), 404-407. https://doi.org/10.14419/ijet.v7i4.8.27279

13. Kozhevnykov, A.O., Dreus, A.Yu., Baochang, Liu, \& Sudakov, A.K. (2018). Drilling fluid circulation rate infuence on the contact temperature during borehole drilling. Naukovyi Visnyk Natsionalnoho Hirnychoho Universytetu. 1(163), 35-43. https://doi.org/10.29202/nvngu/2018-1/14

14. Dreus, A.J., Sudakov, A.K., Kozhevnikov, A.A., \& Vahalin, J.M. (2016). Study on thermal strength reduction of rock formation in the diamond core drilling process using pulse flushing mode. Naukovyi Visnyk Natsionalnoho Hirnychoho Universytetu, 3(153), 5-9.

15. Dreus, A., Sudakov, A., Lysenko, K., \& Kozhevnikov, A. (2016). Investigation of heating of the drilling bits and definition of the energy efficient drilling modes. Eastern-European Journal of Enterprise Technologies. Technologies, 7(81), 41-46. https://doi.org/10.15587/1729$\underline{4061.2016 .71995}$

16. Mustakhimov, A., \& Zeynullin, A. (2020). Scaled-up laboratory research into dry magnetic separation of the Zhezdinsky concentrating mill tailings. Mining of Mineral Deposits, 14(3), 71-77. https://doi.org/10.33271/mining14.03.071 
17. Fedorov, B.V. (2016). Drilling of the wells. Almaty, Kazakhstan: Textbook Almaty, KazNRTU, 368 p.

18. Kozhevnykov, A., Dreus, A., Ratov, B., \& Sudakov, A. (2019). The drill bits: history and modern experience. Rock-Cutting and Metal-Working Tools - The Technique and Technology of its Manufacture and Application, (22), 25-31.

19. Taibergenova, I.K., \& Fedorov, B.V. (2018). Drill bit. Patent RK No. 2016/1222, 1.

20. Gandzhumyan, R.A., Kalinin, A.G., \& Serduk, N.I. (2007). Drilling calculations. Moscow, Russian Federation: RGGU, 668 p.

21. Sudakov, A.K., Dreus, A.Yu., Khomenko O.Ye., \& Sudakova, D.A. (2017). Analytical study of heat transfer in absorptive horizons of borehole at forming cryogenic protecting of the plugging material. Naukovyi Visnyk Natsionalnoho Hirnychoho Universytetu, 3(159), 32-46.

22. Dreus, A.Yu., Bondarenko, V.I., Biletskyi, V.S., \& Lysenko, R.S. (2020). Mathematical simulation of heat and mass exchange processes during dissociation of gas hydrates in a porous medium. Naukovyi Visnyk Natsionalnoho Hirnychoho Universytetu, 5(179). https://doi.org/10.33271/nvngu/2020-5/033

23. Kudaikulov, S.K. (2010). Drilling a well in difficult conditions with removable core drills. Almaty, Kazakhstan: KazNRTU, 243 p.

24. Ratov, B.T., \& Kozhevnykov, A.A. (2019). Dependence of the drilling speed on the frictional forces on the cutters of the rock-cutting tool. Naukovyi Visnyk Natsionalnoho Hirnychoho Universytetu, (1), 21-27. https://doi.org/10.29202/nvngu/2019-1/22

25. Koroviaka, Ye., Rastsvietaiev, V., Dmytruk, O., \& Tykhonenko, V. (2017). Prospects to use biogas of refuse dams of Dnipropetrovsk region (Ukraine) as alternative energy carrier. Mechanics, Materials Science \& Engineering, (11), 1-9. https://doi.org/10.2412/mmse.40.34.18

26. Ratov, B.T., Fedorov, B.V., Khomenko, V.L., Baiboz, A.R., \& Korgasbekov, D.R. (2020). Some features of drilling technology with pde bits. Naukovyi Visnyk Natsionalnoho Hirnychoho Universytetu, (3), 13-19. https://doi.org/10.33271/nvngu/2020-3/013

27. Biletsky, M.T., Ratov, B.T., \& Baiboz, A.R. (2017). Drill bit. Patent for the invention of the Republic of Kazakhstan.

28. Sudakov, A., Dreus, A., Ratov, B., \& Delikesheva, D. (2018). Theoretical bases of isolation technology for swallowing horizons using thermoplastic materials. News of the National Academy of Sciences of the Republic of Kazakhstan. Series of Geology and Technical Sciences, 2(428), 72-80. 